\title{
Adsorption behaviour of 1,3,5-trinitroperhydro-1,3,5-triazine, 2,4-dinitroanisole and 3- nitro-1,2,4-triazol-5-one on commercial activated carbons
}

\author{
William Fawcett-Hirst, ${ }^{a}$ Tracey J. Temple*a , Melissa K. Ladymana ${ }^{a}$ Frederic Coulon ${ }^{b}$ \\ ${ }^{a}$ Cranfield University, Centre for Defence Chemistry, Defence Academy of the United Kingdom, Shrivenham \\ SN6 8LA, UK
}

${ }^{\mathrm{b}}$ Cranfield University, School of Water, Energy and Environment, Cranfield MK43 0AL, UK

\section{Introduction}

In 2012, the US Department of Defence (DoD) required an Insensitive High Explosive (IHE) filling for mortar bombs to replace Composition B, with the aim of increasing personnel safety (Singh et al., 2012). IHE fills are considered safer to use as they are less sensitive to external stimuli as qualified by STANAG 4439 and AOP-39 (NATO, 2010, 2006). IHE encompasses a number of melt-cast formulations that most commonly contain 1,3,5-trinitroperhydro-1,3,5-triazine (RDX), 2,4dinitroanisole (DNAN) and 3-nitro-1,2,4-triazol-5-one (NTO). As well as providing the desired performance characteristics to IHE formulations, these chemicals have unique physiochemical and toxicological properties which pose significant challenges for removal from wastewater effluents at explosive load assembly and pack (LAP) facilities (Arthur et al., 2018). (Table 1)

Table 1: Table of physiochemical properties of energetic materials RDX, DNAN and NTO.

\begin{tabular}{|c|c|c|c|}
\hline Short Name & RDX & DNAN & NTO \\
\hline Full Name & $\begin{array}{l}1,3,5- \\
\text { Trinitroperhydro- } \\
1,3,5 \text {-triazine }\end{array}$ & 2,4-Dinitroanisole & $\begin{array}{l}\text { 3-nitro-1,2,4-triazol-5- } \\
\text { one }\end{array}$ \\
\hline Structure & & & \\
\hline $\begin{array}{l}\text { Solubility in } \\
\text { water }\left(\mathrm{mg.L}^{-1}\right)\end{array}$ & 42 at $20^{\circ} \mathrm{C}^{[1]}$ & 276 at $25^{\circ} \mathrm{C}^{[2]}$ & 16636 at $25^{\circ} \mathrm{C}^{[3]}$ \\
\hline $\begin{array}{l}\text { Oral LD50 } \\
\left(\mathrm{mg.kg}^{-1}\right)\end{array}$ & $100^{[4]}$ & $199^{[5]}$ & $>5000^{[6]}$ \\
\hline $\begin{array}{l}\text { Disassociation } \\
\text { Coefficient } \\
\text { (Kd) }\end{array}$ & $0.11-1.34^{[7]}$ & $0.6-0.63^{[8]}$ & $0.02-0.51^{[9]}$ \\
\hline
\end{tabular}

Compiled from 1 (Pennington and Brannon, 2002), 2 (Taylor et al., 2013), 3 (Spear et al., 1989), 4 (Meyer et al., 2005), 5 (Davies and Provatas, 2006), 6 (London and Smith, 1985), 7 (Katseanes et al., 2016), 8 (Arthur et al., 2017 ), 9 (Mark et al., 2016). 
RDX is a heterocyclic nitramine and is considered the most important high explosive for military application in the United States due to its widespread use (Koutsospyros et al., 2012). The neurotoxic effects of RDX have been known for some time for both humans and other mammals (Kaplan et al., 1965). More recently the mechanism by which RDX causes seizures in humans exposed to it for prolonged periods has been identified (Bannon and Williams, 2015). The low disassociation coefficient (Kd) of RDX indicates it is mobile in soils and water (Monteil-Rivera et al., 2009). Exposure has previously occurred from groundwater contaminated from an ammunition production facility (Fleming et al., 1996). DNAN is a nitro-aromatic compound and has been shown to be toxic with the effects described as "deleterious" to earthworms, algae, bacteria and plants (Dodard et al., 2013). NTO is a white crystalline energetic compound that was first used in explosive formulations in 1987 and in a proposed IHE in 1996 (Lamy et al., 1996; Lee and Coburn, 1988). NTO causes visible yellow discolouration in water and is a source of visible pollution (Tennant et al., 2019). NTO has been assessed by the US EPA as having a toxicity of greater than $5000 \mathrm{mg} \mathrm{kg}^{-1}$, lower than that of table salt (Winstead, 2011). Whilst it may not pose toxicity issues, the visual pollution of NTO and the incidental issues cause by its acidification of water due to its ionic nature means it must be removed from wastewater before it is returned to the environment or municipal system. In addition to its high solubility, NTO has a low Kd and is therefore mobile in soils. It has also been shown to degrade quickly, but the degradation products have not yet been detected in the wider environment and therefore the potential effects remain unknown (Temple et al., 2018). NTO shares some similarities in terms of size, structure, and charge with RDX and DNAN. Therefore, there is a desire to use existing water treatment infrastructure in order to process water contaminated through production of munitions using newer IHE compositions containing these materials, as has been recorded at Picatinny Arsenal in the United States (Felt et al., 2013).

Adsorption is widely used in drinking water, wastewater and groundwater treatments to remove organic chemicals (Ali et al., 2012; Bricka and Fleming, 1995; Gupta and Saleh, 2013). Adsorption is a surface phenomenon caused by intermolecular Van Der Waals forces between molecules, which attract and bind contaminants (or sorbates) to a sorbent surface. As a result, surface area is the primary driver in adsorptive capacity and is itself dependent on the preparation method of the activated carbon (AC) which can change surface groups as well as the primary source material which provides the inherent material structure (Jain et al., 2016). The commercial success of AC for the adsorption process is due to a combination of its efficacy and cost effectiveness for removing a wide range of contaminants such as dyes (Robinson et al., 2001), pharmaceuticals (Garcia-Mateos et al., 2015) and pesticides (Salman et al., 2011) from water as well as inorganics such as heavy metals (Mohan and Pittman, 2007). The structure and shape of energetic materials of interest share similarities to 
pharmaceuticals such as paracetamol and ibuprofen in the case of DNAN and Metronidazole in the case of NTO (Figure 1).<smiles>CC(C)Cc1ccc(C(C)C(=O)O)cc1</smiles><smiles>Cc1ncc([N+](=O)[O-])n1CCO</smiles><smiles>CC(=O)Nc1ccc(C)cc1</smiles>

Figure 1: Chemical structures of the pharmaceutical's ibuprofen metronidazole and paracetamol.

There are two modes of adsorption that occur, film diffusion and intra-particle diffusion. Film diffusion occurs when IHE constituents move from the bulk liquid to the AC surface. After each adsorption site has interacted with the IHE constituent a monolayer is formed after which no further adsorption can take place until the contaminant has been drawn into the internal pore structure of the AC by intra-particle diffusion which then becomes the rate limiting step (Sun et al., 2018). AC has been successfully used as a treatment method for energetic materials including 2,4,6-trinitotoluene (TNT), RDX, and 1,3,5,7-tetranitro-1,3,5,7-tetrazoctane (HMX) at both a laboratory and industrial scale (Hinshaw et al., 1987; Morley et al., 2005) as well as in the remediation of contaminated groundwater (Bricka and Fleming, 1995; Payne et al., 2013; Wujcik et al., 1992). AC comes in a variety of forms that are chosen based on the application. Powdered AC is used for water treatment, often as a tertiary treatment step or in conjunction with biological degradation (Altmann et al., 2014). Sheet carbon is used in removal of volatile organic compounds from gas streams (Son et al., 2016) whilst water treatment is most often undertaken using Granular AC in a column or fluidised bed. Granular AC has also been the subject of research on the adsorption of RDX (Morley and Fatemi, 2010), DNAN (Boddu et al., 2009) and NTO (Chew et al., 2017) from water. DNAN has been shown to be removable from solution in water by GAC adsorption with efficiency of up to $99 \%$ (Boddu et al., 2009). NTO was shown to be removed from solution using AC under flow conditions but batch adsorption studies were not reported meaning adsorption kinetics could not be investigated (Chew et al., 2017). Explosive wastewater treatment facilities have been reported to use Calgon's Filtrasorb 
200 due to its efficiency and relatively low cost (Bricka and Fleming, 1995; Fleming et al., 1996; Hinshaw et al., 1987). ACs with a larger particle size such as Atochem $8 \times 30$ mesh AC have also been reported to perform well at removal of explosives from wastewater (Roy F Weston Inc. et al., 1990).

However, current AC based systems designed to treat TNT and RDX wastewater have proved inefficient in the treatment of IHE wastewater (Felt et al., 2013). Analysis of IHE concentrations in (LAP) processing wastewater from Picatinny Building 809 has been reported to be 1400, 137 and 33 $\mu \mathrm{g} / \mathrm{L}$ for DNAN, NTO and RDX, respectively (Felt et al., 2013).

This inefficiency is reportedly due to high concentrations of NTO in the wastewater, which can be two orders of magnitudes higher than RDX and TNT concentrations in typical wastewater. However, the inefficiency could be alternatively attributed to poor compatibility with the specific AC used or other operational parameters of the system. Despite the difficulty of treating IHE wastewater using current systems, adsorptive treatment remains an attractive proposition due to the ease of installation and operation of adsorptive systems.

With regards to DNAN, it has been successfully removed from wastewater using natural fibres such as lignin (Saad et al., 2012) and cellulose (Shukla and Poda, 2016). However, the removal efficiency of DNAN per gram of lignin adsorbent was 3-10 times lower than for ACs (Boddu et al., 2009) meaning that $\mathrm{AC}$ still has an important role to play in removal of DNAN from waste water with comparison of adsorption kinetics of DNAN between different ACs providing important information as to how the wastewater treatment process can be optimised. Other methods for treatment of DNAN contaminated waste water include an anaerobic fluidised bed reactor with an ethanol feedstock (Platten et al., 2013) and treatment with zero-valent iron followed by microbial reduction (Ahn et al., 2011). DNAN has also been biodegraded alongside NTO under aerobic conditions in batch tests using cultures derives from soil, compost and anaerobic digester sludge (Richard and Weidhaas, 2014). NTO has been successfully degraded in wastewater using electrolysis (Cronin et al., 2007; Wallace et al., 2009) with degradation of $95 \%$ to Azoxytriazolone from a starting concentration of 0.1mol. $\mathrm{L}^{-}$ 1. Although promising, these new methods may be difficult to retrofit to some LAP facilities, due to physical footprint changes, technology readiness levels or additional permitting requirements (Felt et al., 2013). In addition, Azoxytriazolone is still considered to be an explosive and could be toxic meaning that the potential safety and environmental hazards remain unaddressed (Cronin et al., 2007).

Due to the issues and challenges identified in treating IHE wastewater with novel treatment methods carbon adsorption remains a promising method of treatment. However, further research needs to be conducted on the suitability and efficacy of different commercially available ACs to remove IHE 
from wastewater effluents. This is so that the characteristics that affect adsorption can be identified and applied to the use of alternative adsorptive materials such as biochars. It is also important to ascertain what changes to the adsorption process take place when mixtures contain more than one energetic material as well as the adsorption kinetics of each IHE component. This is in order to optimise the wastewater treatment process for Insensitive Munitions (IM) that contain IHE before their widespread adoption and use.

One way in which adsorptive processes are measured and compared is through the use of isotherms (Ncibi, 2008). The Langmuir, Freundlich and Temkin isotherm models are used to evaluate adsorption each with their own set of assumptions about the process taking place with the Langmir and Freundlich isotherms most reported (Ahmed et al., 2016). The Langmuir isotherm assumes the formation of a monolayer on the surface of the adsorbent after which no further adsorption occurs (Dada et al., 2012). The Freundlich isotherm has been used to evaluate sorption of energetic materials to AC (Rajagopal and Kapoor, 2001) as well as dyes, pharmaceuticals and other sorbates (Zhou et al., 2015). The Temkin isotherm specifically takes into account the interactions between the adsorbate and the adsorbent during the adsorption process and assumes that the binding energy is uniformly distributed (Dada et al., 2012). By plotting experimental data and quantifying the fit to the different isotherm models the best fit can be ascertained and therefore an insight into assumptions that best describe the actual adsorption of IHE taking place.

In this study, three commercial AC were selected including Calgon Filtrasorb 200 (F200), Cabot Norit $8 \times 30$ mesh (N830) and Calgon Centaur (Centaur). Filtrasorb 200 was chosen due to use in previous work removing energetic materials including RDX from solution (Fleming et al., 1996). Norit 830 was chosen so that the effect of larger particle size could be investigated. Centaur has the same particle size as F200 but was chosen to investigate the effect of, in-situ reduction of contaminants as well as adsorption as advertised (Calgon Carbon, 2015). The enhanced electrocatalytic performance is due to the nitrogen atom replacing carbon in the matrix of the material, increasing the electron density as well as the ability of pyridinic nitrogen to promote reaction on the material surface (Lv et al., 2018; Yu et al., 2019). This work assesses the performance of the three commercial AC adsorbents for the removal of IHE constituents of wastewater effluent. This was achieved by a combination of modelling experimental data from adsorption processes, to determine the mechanisms of adsorption, and comparison of the timed adsorption of individual and mixed IHE constituents in solution.

\section{Materials and Methods}




\subsection{Preparation of the IHE samples}

IHE samples were prepared using RDX, DNAN and NTO. RDX was provided by an industrial partner and was recrystallized prior to use to ensure purity of $>99 \%$. DNAN was purchased from Alfa Aesar at a purity of $98 \%$. NTO was synthesized in house using the method detailed in (Lee and Coburn, 1988). Acetonitrile was purchased from Fisher Chemical at a purity of $\geq 99.9 \%$. The individual IHE constituents were dissolved by agitation using a Heidolph MR3002 with a magnetic bar stirrer in distilled water at $\mathrm{pH} 6$ to create stock solutions. Distilled water was also used to dilute the IHE stock solutions to the required concentrations for equilibrium and timed adsorption tests (Table 2). All commercial ACs used in this research were provided by their respective manufacturers, carbon types and specification are listed in Table 3. A single grain of each AC was imaged using a Hitachi SU5000 Scanning Electron Microscope (SEM) at 10kV, spot size of $6.4 \mathrm{~mm}$ and a magnification of 120x.

All experiments were carried out in a thermally regulated environmental chamber $\left(21{ }^{\circ} \mathrm{C} \pm 0.6{ }^{\circ} \mathrm{C}\right)$ (Morley and Fatemi, 2010). Tests using a mixture of IHE constituents were carried out with a solution containing each individual constituent at a concentration of $10 \mathrm{mg} . \mathrm{L}^{-1}$ with all experiments carried out in triplicate. In addition, it was assumed that during the tests, IHE adhesion to the interior of the container was negligible so any change in the mass of IHE in solution was equal to the amount of IHE adsorbed onto the AC.

Table 2: Concentrations of IHE constituents used for equilibrium and timed adsorption tests.

\begin{tabular}{|l|c|c|c|c|c|c|}
\hline \multicolumn{7}{|c|}{ Concentrations of IHE Constituents in individual solutions (mg. $\mathbf{L}^{-\mathbf{1}}$ ) } \\
\hline RDX & 40 & 30 & 20 & 15 & \multicolumn{2}{c|}{10} \\
\hline DNAN & 150 & 120 & 75 & 50 & 25 & 12.5 \\
\hline NTO & 1400 & 700 & 350 & 140 & 70 & 14 \\
\hline
\end{tabular}

Table 3: Specification of AC materials

\begin{tabular}{|l|l|c|c|c|c|l|}
\hline $\begin{array}{c}\text { Activated } \\
\text { Carbon }\end{array}$ & \multicolumn{1}{|c|}{$\begin{array}{c}\text { Source } \\
\text { Material }\end{array}$} & $\begin{array}{c}\text { Minimum } \\
\text { Iodine } \\
\text { Number } \\
(\mathbf{m g} / \mathbf{g})\end{array}$ & $\begin{array}{c}\text { Minimum } \\
\text { Abrasion } \\
\text { Number }\end{array}$ & $\begin{array}{c}\text { Density } \\
\text { (g/ml) }\end{array}$ & $\begin{array}{c}\text { Particle } \\
\text { Diameter }(\mathbf{m m})\end{array}$ & Data Sheet \\
\hline $\begin{array}{l}\text { Norit GAC } \\
830\end{array}$ & $\begin{array}{l}\text { bituminous } \\
\text { coal }\end{array}$ & 920 & 75 & 0.50 & $0.6-2.36$ & $\begin{array}{l}\text { (Cabot } \\
\text { Corportion, 2011) }\end{array}$ \\
\hline $\begin{array}{l}\text { Filtrasorb } \\
200\end{array}$ & $\begin{array}{l}\text { bituminous } \\
\text { coal }\end{array}$ & 850 & 75 & 0.58 & $0.55-0.75$ & $\begin{array}{l}\text { (Calgon Carbon, } \\
\text { 2019) }\end{array}$ \\
\hline $\begin{array}{l}\text { Centaur } \\
12 \times 40\end{array}$ & $\begin{array}{l}\text { bituminous } \\
\text { coal }\end{array}$ & 825 & 75 & 0.56 & $0.9-1.1$ & $\begin{array}{l}\text { (Calgon Carbon, } \\
\text { 2015) }\end{array}$ \\
\hline
\end{tabular}

\subsection{Evaluation of Adsorption Equilibria}


Stock solution (50 mL) of RDX, DNAN or NTO in water (Table 2) were added to commercial AC $(20 \mathrm{mg}$ ) which had been prepared by pulverisation with a pestle and mortar and poured into $60 \mathrm{~mL}$ amber glass vials. (Maneerung et al., 2016)(Morley and Fatemi, 2010). Samples were agitated on a Stuart SSL 1 flatbed orbital shaker for 7 days at $150 \mathrm{rpm}$ (Metcalf \& Eddy, 2014). Sub-samples were collected before contact with the AC (T0) and after seven days (T1) (Maneerung et al., 2016). Samples were left to settle for 30 seconds and sub-samples were extracted. Samples with a concentration higher than $50 \mathrm{mg} \mathrm{L}^{-1}$ were diluted with water 1:1 $\mathrm{ACN}$ :Water before analysis by HPLC.

\subsection{Evaluation of Adsorption over time}

Stock solution (100 mL) of RDX, DNAN or NTO (Table 2) (5 of RDX, 6 of DNAN, 6 of NTO) were added to $40 \mathrm{mg}$ of each AC (Maneerung et al., 2016) as supplied by the manufacturer in $500 \mathrm{~mL}$ amber glass jars. The tests were agitated on a Stuart SSL 1 flatbed orbital shaker (150 rpm) for 6 hours. Samples were taken before contact with the AC and at 0.5, 1, 2, 3, 4, 5 and 6 hours, each after a settling period of 30 seconds. Sub-samples were taken and diluted with 1:1 ACN:Water to below $50 \mathrm{mg} . \mathrm{L}^{-1}$ if necessary before analysis by HPLC. For the mixed IHE tests, the same method was used as for the individual constituents with a solution containing $10 \mathrm{mg} . \mathrm{L}^{-1}$ of each IHE constituent.

\subsection{High Performance Liquid Chromatography}

Aliquots of $10 \mu \mathrm{L}$ from each of the sub-samples taken during the experiment were analysed using High Performance Liquid Chromatography (HPLC). The HPLC system consisted of a Waters Alliance 2695 fitted with a Waters 996 photodiode array detector. Separations were performed with a $150 \times 4.6 \mathrm{~mm}$ Agilent ZORBAX Eclipse Plus C18 column maintained at $30^{\circ} \mathrm{C}$. The mobile phase used was a 40:60 acetonitrile/water mix at a flow rate of 1.5 mL.min ${ }^{-1}$ and was calibrated against reference samples of each IHE constituent at known concentrations from the highest initial concentration of each to $0.05 \mathrm{mg} . \mathrm{L}^{-1}$. Detection wavelengths, linearity, limits of detection and quantifiability and precision are displayed in Table 4. Precision was determined using six replicate injections at the same concentration for each IHE constituent and calculating the percentage error between injections to six standard deviations. 
Table 4: Quality assurance data for HPLC methodology.

\begin{tabular}{|l|c|c|c|l|}
\hline Chemical & $\begin{array}{l}\text { Wavelength } \\
(\mathbf{n m})\end{array}$ & $\begin{array}{l}\text { Linearity } \\
\left(\mathbf{R}^{\mathbf{2}}\right)\end{array}$ & $\begin{array}{l}\text { LOD/ LOQ } \\
(\boldsymbol{\mu L} \mathbf{m L} \mathbf{- 1})\end{array}$ & $\begin{array}{l}\text { Precision } \\
(\boldsymbol{\%})\end{array}$ \\
\hline RDX & 235 & 0.9998 & $0.04 / 0.40$ & 1.56 \\
\hline DNAN & 296 & 1 & $0.05 / 0.45$ & 1.25 \\
\hline NTO & 315 & 0.9997 & $0.04 / 0.42$ & 1.80 \\
\hline
\end{tabular}

\subsection{Data Analysis}

Data generated from the experiments was analysed using Microsoft Excel 2016. The statistical validity of adsorptive capacities was evaluated using standard error of mean to evaluate if differences between the mean values of adsorptive capacity where great enough to not overlap and therefore be relevant. Data points for the timed adsorption tests were evaluated using standard deviation to evaluate the variability between the individual replicates for each data point. In order to infer the adsorption kinetics taking place between the commercial ACs and the IHE constituents, equilibrium experimental data was plotted using the Langmuir, Freundlich, and Temkin isotherms. For each isotherm model the data was plotted with a linear trend line using Microsoft Excel software which gives a regression value $\mathrm{R}^{2}$ for the data set (Arthur et al., 2017).

\section{Results and Discussion}

\subsection{SEM Analysis of Activated Carbons}

Scanning electron microscope (SEM) images were used to initially observe the surface morphology of a single grain of each AC used (Figure 2). The SEM images shown that the surface of F200 (Figure 2b) is flatter and more rounded compared to Cabot Norit 830 (Figure 2a). This indicates a reduction in available surface area on the F200 carbon grain for sorption to take place and therefore providing a more homogenous surface on which adsorption can occur. Despite multiple grains being observed with consistent lighter patches visible on the Centaur carbon (2c), it is unclear whether this was a result of the modification carried out. However, the visible evidence of crags and valleys on the grain surface translate into additional surface area for adsorption to take place (Mohan et al., 2011). 

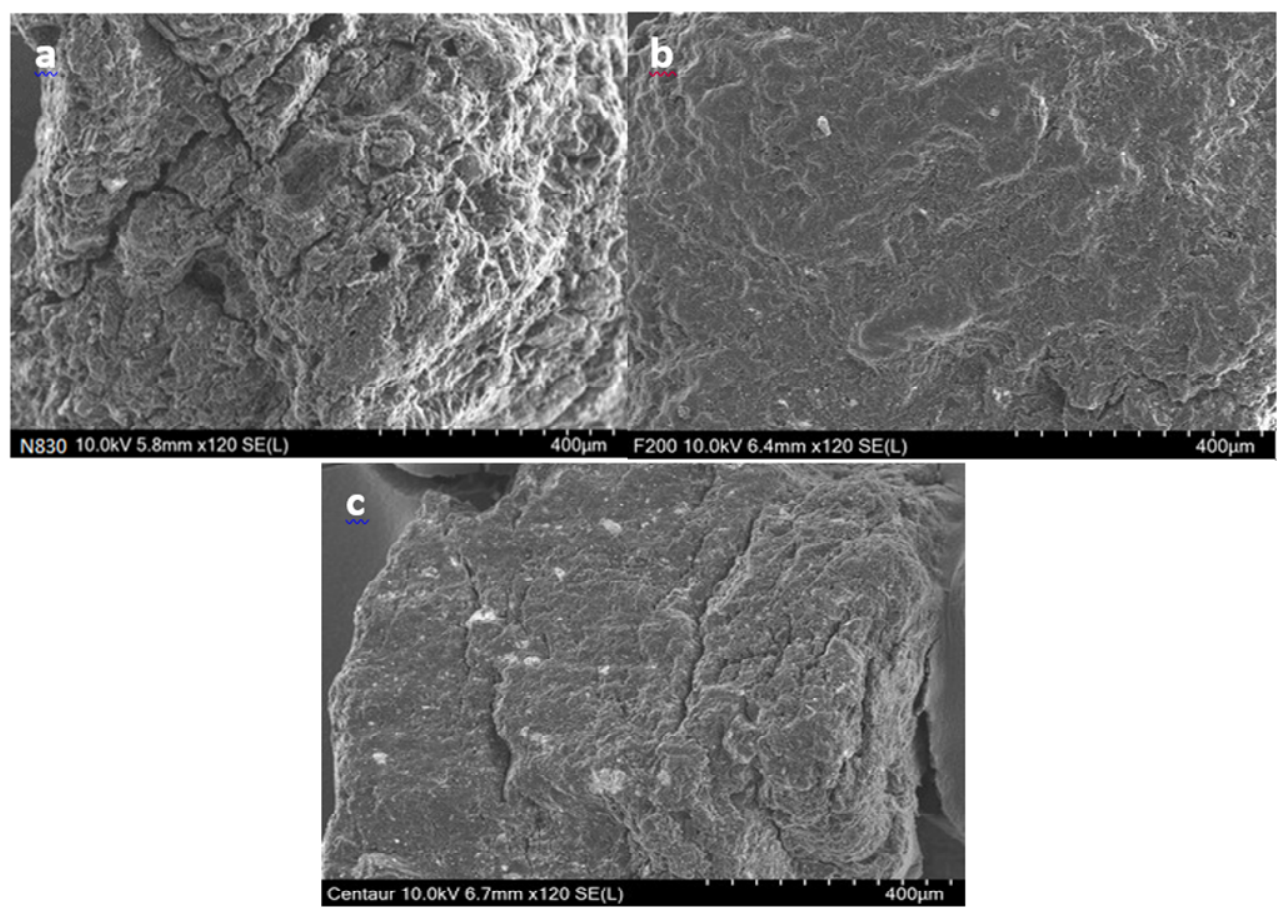

Figure 2: SEM Images of Cabot Norit 830 (a) Calgon Filtrasorb 200 (b) and Calgon Centaur (c) granular activated carbons, Cranfield University 2019.

\subsection{Adsorptive Capacity}

Adsorptive capacity was calculated from the equilibrium data as the total amount of IHE constituent adsorbed per gram of pulverised AC. The adsorptive capacities for each AC and IHE constituent can be seen in Tables 5-7. At low concentrations of RDX ( $<10 \mathrm{ppm})$, the adsorptive capacity of all the ACs was comparable. A trend is shown throughout where adsorptive capacity increases with concentration of IHE in solution, e.g. when the AC is fully saturated then adsorptive capacity will no longer increase with increases in initial concentration. As expected from previous work all ACs tested removed high concentrations of RDX from solution (Morley and Fatemi, 2010). The results also show that any one of the ACs tested would be effective at RDX adsorption as the levels expected in wastewater treatment facilities are low enough that saturation of the AC does not occur (Felt et al., 2013).

Table 5: Adsorptive capacity $\left(\mathrm{mg} \cdot \mathrm{g}^{-1}\right)$ of RDX at atmospheric pressure and constant temperature $\left(21^{\circ} \mathrm{C} \pm\right.$ $0.6^{\circ} \mathrm{C}$ ) including the standard error of the mean.

\begin{tabular}{|l|c|c|c|c|c|}
\hline \multirow{2}{*}{$\begin{array}{c}\text { Activated } \\
\text { Carbon }\end{array}$} & \multicolumn{5}{|c|}{ RDX (mg. $\left.\mathrm{L}^{-1}\right)$} \\
\cline { 2 - 6 } & 40 & 30 & 20 & 15 & 10 \\
\hline Norit 830 & $78.4 \pm 1.2$ & $58.7 \pm 1.2$ & $40.1 \pm 0.2$ & $30.8 \pm 0.1$ & $20.5 \pm 0.1$ \\
\hline Filtrasorb 200 & $76.0 \pm 0.5$ & $58.2 \pm 0.3$ & $33.6 \pm 0.1$ & $22.6 \pm 0.2$ & $19.5 \pm 0.2$ \\
\hline Centaur & $76.9 \pm 1.3$ & $58.5 \pm 0.3$ & $33.7 \pm 0.1$ & $22.9 \pm 0.1$ & $19.6 \pm 0.2$ \\
\hline
\end{tabular}

Table 6 shows the equilibrium adsorptive capacities of each AC for DNAN. The adsorptive capacity of the three ACs started to plateau at initial DNAN concentrations greater than $120 \mathrm{mg} . \mathrm{L}^{-1}$ as 
evidenced by the decreasing rate of change between adsorptive capacity for $120 \mathrm{mg} . \mathrm{L}^{-1}$ and $150 \mathrm{mg} . \mathrm{L}^{-}$ ${ }^{1}$ (Figure 3). This suggests that the maximum adsorptive capacity is being approached at which higher initial concentrations of DNAN would not result in higher adsorptive capacity for the AC due to it being saturated. In a previous study conducted by Boddu et al, (2009), concentrations were two orders of magnitude lower and therefore the plateau of adsorption capacity effect was not observed although adsorptive capacities for the initial concentrations tested were similar.

Table 6: Adsorptive capacity $\left(\mathrm{mg} \cdot \mathrm{g}^{-1}\right)$ of DNAN at atmospheric pressure and constant temperature $\left(21^{\circ} \mathrm{C} \pm 0.6^{\circ} \mathrm{C}\right)$ including the standard error of the mean.

\begin{tabular}{|l|c|c|c|c|c|c|}
\hline \multirow{2}{*}{$\begin{array}{c}\text { Activated } \\
\text { Carbon }\end{array}$} & \multicolumn{5}{|c|}{ DNAN $\left(\mathrm{mg.L}^{-1}\right)$} \\
\cline { 2 - 7 } & 150 & 120 & 75 & 50 & 25 & 12.5 \\
\hline Norit 830 & $337.2 \pm 9.6$ & $292.4 \pm 11.4$ & $182.5 \pm 11.0$ & $129.9 \pm 3.6$ & $53.5 \pm 3.4$ & $27.6 \pm 1.5$ \\
\hline Filtrasorb 200 & $296.6 \pm 16.2$ & $273.8 \pm 18.8$ & $178.8 \pm 11.3$ & $126.1 \pm 6.7$ & $52.5 \pm 2.6$ & $27.1 \pm 1.0$ \\
\hline Centaur & $296.7 \pm 16.7$ & $274.4 \pm 9.4$ & $178.8 \pm 9.2$ & $127.8 \pm 3.0$ & $52.9 \pm 2.9$ & $27.4 \pm 1.4$ \\
\hline
\end{tabular}

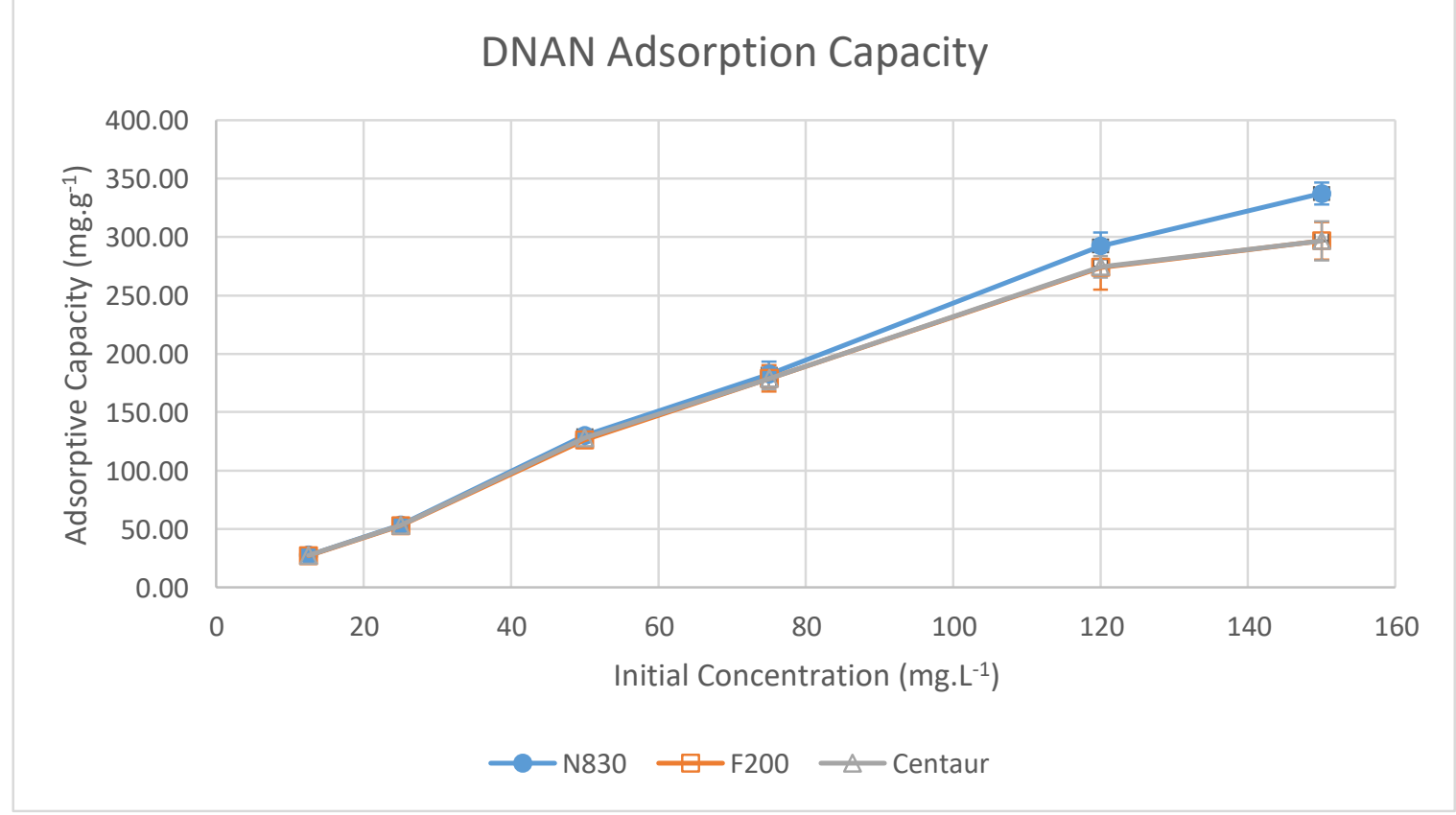

Figure 3: DNAN adsorption capacities for 3 ACs from a series of initial concentrations.

Norit 830 had the highest adsorptive capacity of all three ACs across the initial concentrations of NTO from $14 \mathrm{mg} . \mathrm{L}^{-1}$ to $1400 \mathrm{mg} . \mathrm{L}^{-1}$ as expected due to its higher iodine number, whereas Centaur had the lowest (Table 7). In addition, Centaur was not as sensitive to changes in initial concentration to adsorptive capacity and had the lowest adsorptive capacity of the three ACs tested at all concentration higher than $14 \mathrm{mg} \cdot \mathrm{L}^{-1}$. This suggests that there was an inhibition to adsorption occurring due to the pyridinic modification on the surface and the ionic nature of NTO causing an electrostatic repulsion that inhibited adsorption. A plot of the equilibrium adsorptive capacity of the ACs against the initial concentration of NTO is linear, indicating that the saturation adsorptive capacity of the ACs has not yet been reached (Figure 4). 
Table 7: Adsorptive capacity $\left(\mathrm{mg}^{-\mathrm{g}^{-1}}\right)$ of NTO at atmospheric pressure and constant temperature $\left(21^{\circ} \mathrm{C} \pm 0.6^{\circ} \mathrm{C}\right)$ including the standard error of the mean.

\begin{tabular}{|l|l|l|l|l|l|c|}
\hline \multirow{2}{*}{$\begin{array}{c}\text { Activated } \\
\text { Carbon }\end{array}$} & \multicolumn{7}{|c|}{ NTO $\left(\mathrm{mg}^{-\mathrm{L}^{-1}}\right)$} \\
\cline { 2 - 7 } & \multicolumn{1}{|c|}{1400} & \multicolumn{1}{|c|}{700} & \multicolumn{1}{c|}{140} & 70 & 14 \\
\hline Norit 830 & $2285.2 \pm 401.1$ & $1145.1 \pm 250.9$ & $579.0 \pm 126.0$ & $288.4 \pm 12.6$ & $122.9 \pm 1.5$ & $33.5 \pm 4.1$ \\
\hline Filtrasorb 200 & $1734.8 \pm 188.4$ & $884.2 \pm 157.3$ & $498.5 \pm 92.1$ & $262.2 \pm 1.9$ & $105.1 \pm 7.3$ & $33.4 \pm 4.3$ \\
\hline Centaur & $1270.0 \pm 337.7$ & $558.1 \pm 30.8$ & $267.5 \pm 3.7$ & $78.4 \pm 75.3$ & $61.9 \pm 27.5$ & $31.5 \pm 5.3$ \\
\hline
\end{tabular}

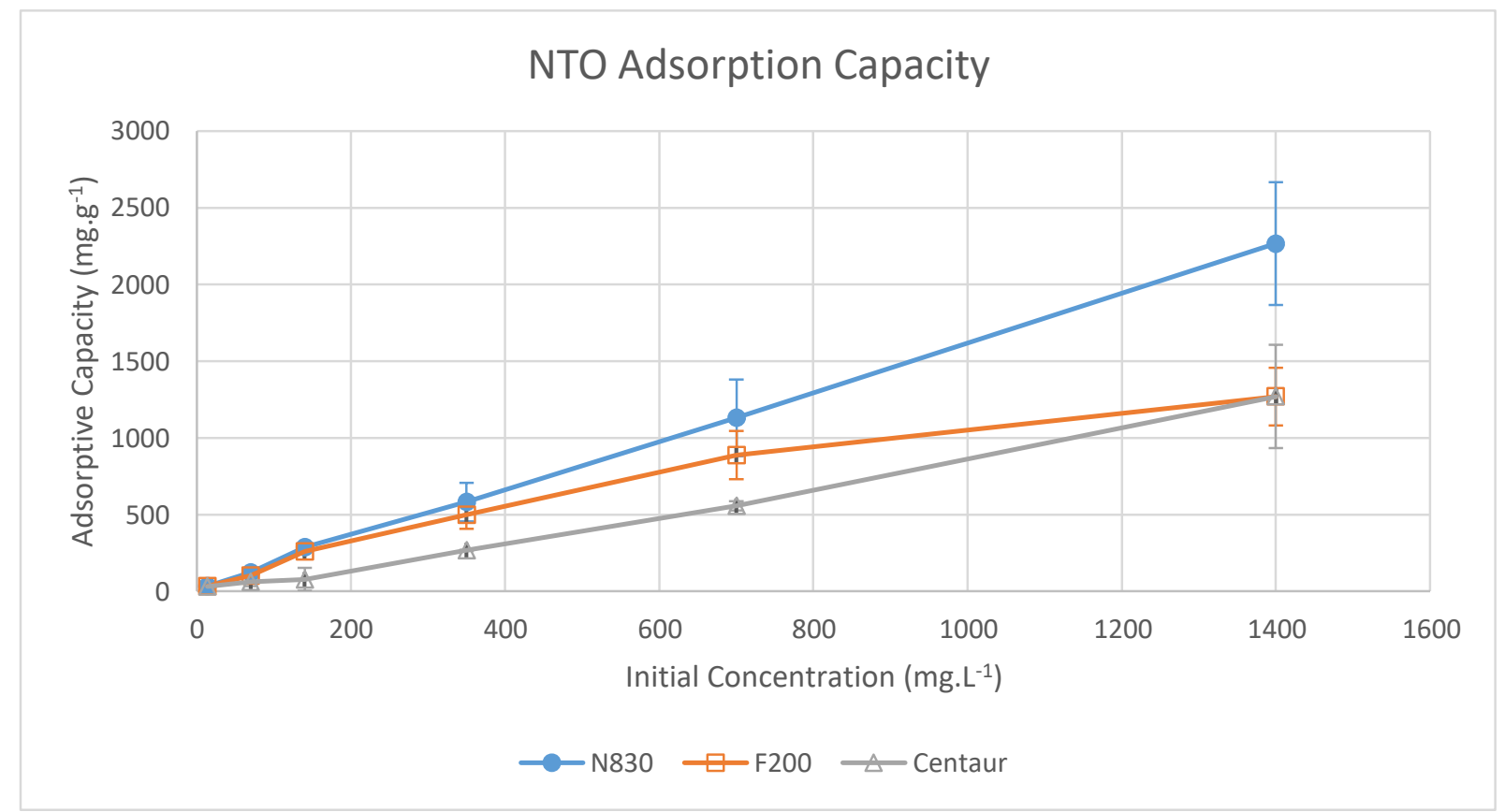

Figure 4: NTO adsorption capacities for 3 ACs from a series of initial concentrations.

\subsection{Isotherm Model Fit}

Each isotherm model allowed extrapolation from the data points that had been measured (Table 8). By comparing the linear regression values between isotherm models, the assumptions that underpin each isotherm were verified for each combination of IHE and AC. Isotherm coefficients are also used to estimate the amount of $\mathrm{AC}$ required to treat contaminated water when process details such as flow rate and inlet concentration are known.

Adsorption of RDX was consistent between all ACs tested, with the Freundlich isotherm model providing the best fit to the empirical data. Poor fit to the Langmuir isotherm suggests that the formation of a monolayer does not best represent the method of adsorption taking place and at the concentrations tested. This is due to the Freundlich isotherm taking into account the heterogeneous surface of the ACs as seen in Figure 2.

Table 8: Regression factors for linear isotherm equation compared to empirical data plots for all ACs and IHEs tested. 


\begin{tabular}{|c|l|r|r|r|}
\hline \multirow{3}{*}{ Langmuir } & RDX & 0.8281 & 0.6961 & 0.7706 \\
& DNAN & 0.9945 & 0.9990 & 0.9978 \\
\cline { 2 - 5 } & NTO & 0.0446 & 0.7479 & 0.4545 \\
\hline \multirow{3}{*}{ Freundlich } & RDX & 0.9566 & 0.9439 & 0.9806 \\
\cline { 2 - 5 } & DNAN & 0.9815 & 0.6910 & 0.9652 \\
\cline { 2 - 5 } Temkin & NTO & 0.9465 & 0.9427 & 0.8668 \\
\hline \multirow{3}{*}{ RDX } & DNAN & 0.8912 & 0.9274 & 0.9306 \\
\cline { 2 - 5 } & NTO & 0.9724 & 0.8480 & 0.9815 \\
\hline & & 0.6067 & 0.5573 & 0.5225 \\
\hline
\end{tabular}

The best fit of the DNAN data was to the Langmuir isotherm across all ACs tested, suggesting that a monolayer is formed on the ACs and makes film diffusion the limiting step of adsorption (Sun et al., 2018). In addition, the inter-adsorbate interactions indicated by correlation to the Temkin isotherm model had more of an effect when adsorbing DNAN to N830 than NTO and RDX. The interaction between the DNAN molecules and its non-polar nature meant that film diffusion was the limiting step of the adsorption process rather than intra-particle diffusion. The Temkin isotherm continues to provide high regression factors as the DNAN is also still interacting with itself during adsorption.

NTO showed a correlation to the Freundlich isotherm although had a much greater variability between the ACs tested indicating that there were other interactions affecting the adsorption behaviours. Poor fit to the Temkin isotherm suggests limited inter-adsorbate interactions between NTO molecules which was attributed to the disassociation of NTO in solution. Very low regression factor to the Langmuir isotherm shows a monolayer was formed quickly and before diffusion was overtaken by intra-particle diffusion as the limiting step of adsorption. This was due to the charge differential across the NTO molecule when dissolved in water making disruption of the boundary film layer at the carbon surface easier. The concentration gradient between each side of the film barrier then inhibits further adsorption until NTO is absorbed into the internal structure of the AC allowing further surface adsorption to take place.

\subsection{Rate of adsorption over time}

Evaluation of timed adsorption was undertaken using AC in granular form as provided by the manufacturer. By comparing the rate of IHE constituent adsorption between each of the ACs tested it was possible to identify the affinity of each AC for the individual IHE constituents in solution. Figures 5 and 7 both initially display high rates of adsorption with subsequent slowing resulting in a logarithmic curve. This was expected based on the amount of IHE in solution and availability of unreacted $\mathrm{AC}$ and would continue until equilibrium was reached. There was no significant difference 
between the rates of adsorption of the ACs tested for adsorption of RDX which demonstrates that any of them would be suited to RDX removal from wastewater.

Timed adsorption experiments for DNAN are shown in Figure 5 wherein Norit 830 consistently performs well in adsorbing DNAN which correlated with the adsorptive capacity data (Table 6). The larger particle size of N830 provided a greater external surface area for film diffusion which was identified to be the predominant adsorption mechanism for DNAN. Despite the total surface area being comparable between all ACs, the greater percentage external surface area of N830 meant there was a greater area for film diffusion to take place initially when compared to the greater percentage of internal surface area of the other ACs tested.

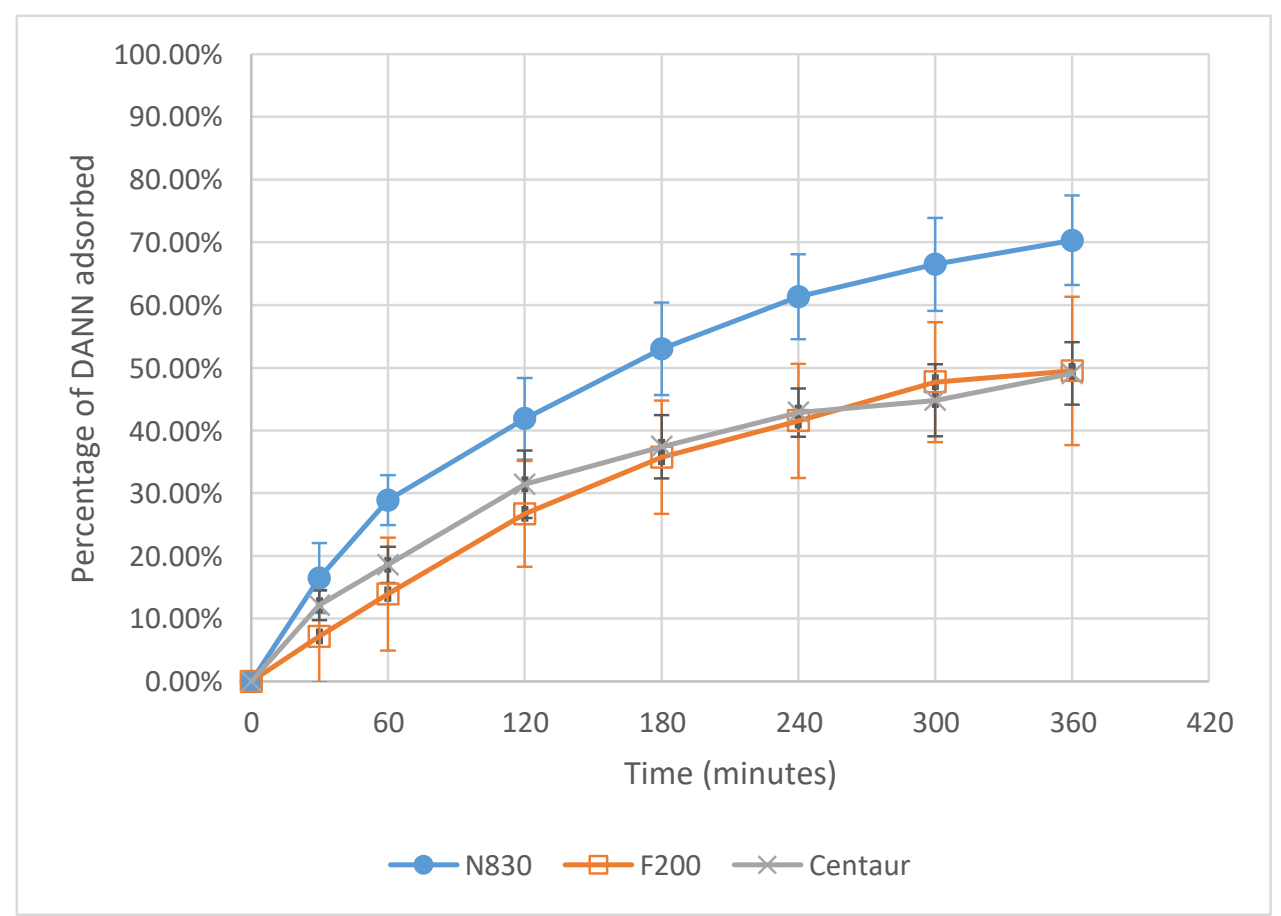

Figure 5: DNAN sorption over time from an aqueous solution of $120 \mathrm{mg}$ DNAN.L ${ }^{-1}$ All tests conducted in triplicate.

The results for the adsorption of NTO are inconclusive for concentrations greater than $350 \mathrm{mg} . \mathrm{L}^{-1}$. The AC was quickly saturated with NTO and then underwent repeated adsorption and desorption cycles (Figure 6). This behaviour in batch experiments using AC was also seen in the work by Chew et al. (2017). The cycling behaviour is due to the higher rate of adsorption from the bulk fluid to the surface film compared to intra-particle adsorption. As the concentration gradient across the boundary film layer fluctuates the NTO adsorbs and desorbs to compensate. Timed tests that were left for 7 days stabilised to equilibrium as demonstrated in the equilibrium experiments (Section 3.2). The expected concentration of NTO in contaminated wastewater was reported as $1400 \mathrm{mg} . \mathrm{L}^{-1}$ (Felt et al., 2013), potentially up to saturation (16636 mg. $\mathrm{L}^{-1}$ ) (Spear et al., 1989). These adsorption tests suggest 
that a full-scale treatment facility would require large masses of $\mathrm{AC}$ that may need to be replaced after each treatment cycle correlating with the conclusions of Felt et al. (Felt et al., 2013). However, if low volumes of contaminated wastewater were produced or larger volumes infrequently a batch process could be used. At lower concentrations $\left(<70 \mathrm{mg} . \mathrm{L}^{-1}\right)$ the adsorption of NTO over time initially undergoes a rapid adsorption phase, followed by a slower phase as equilibrium is reached (Figure 7).

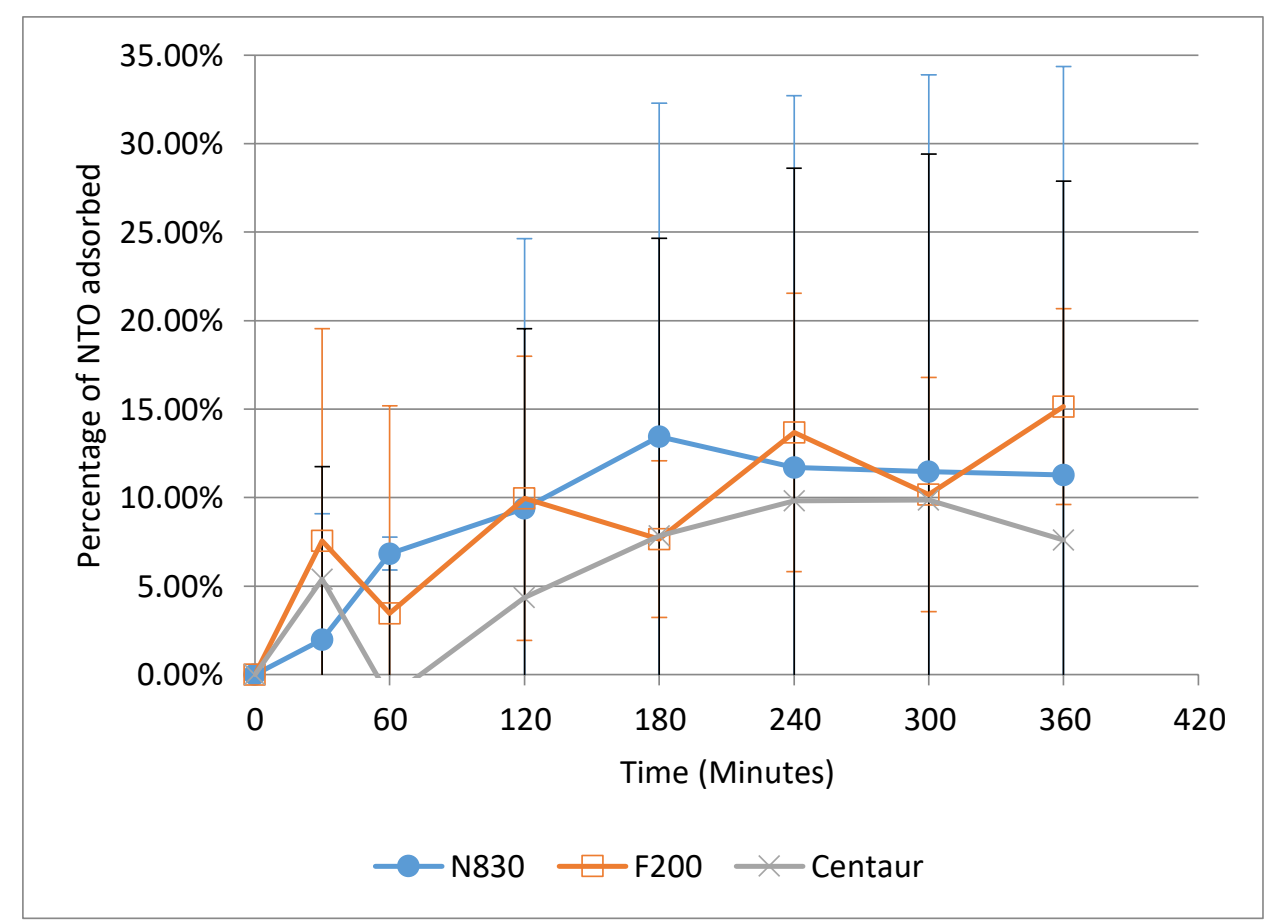

Figure 6: NTO sorption over time from an aqueous solution of $350 \mathrm{mg}$ NTO. $\mathrm{L}^{-1}$ All tests conducted in triplicate.

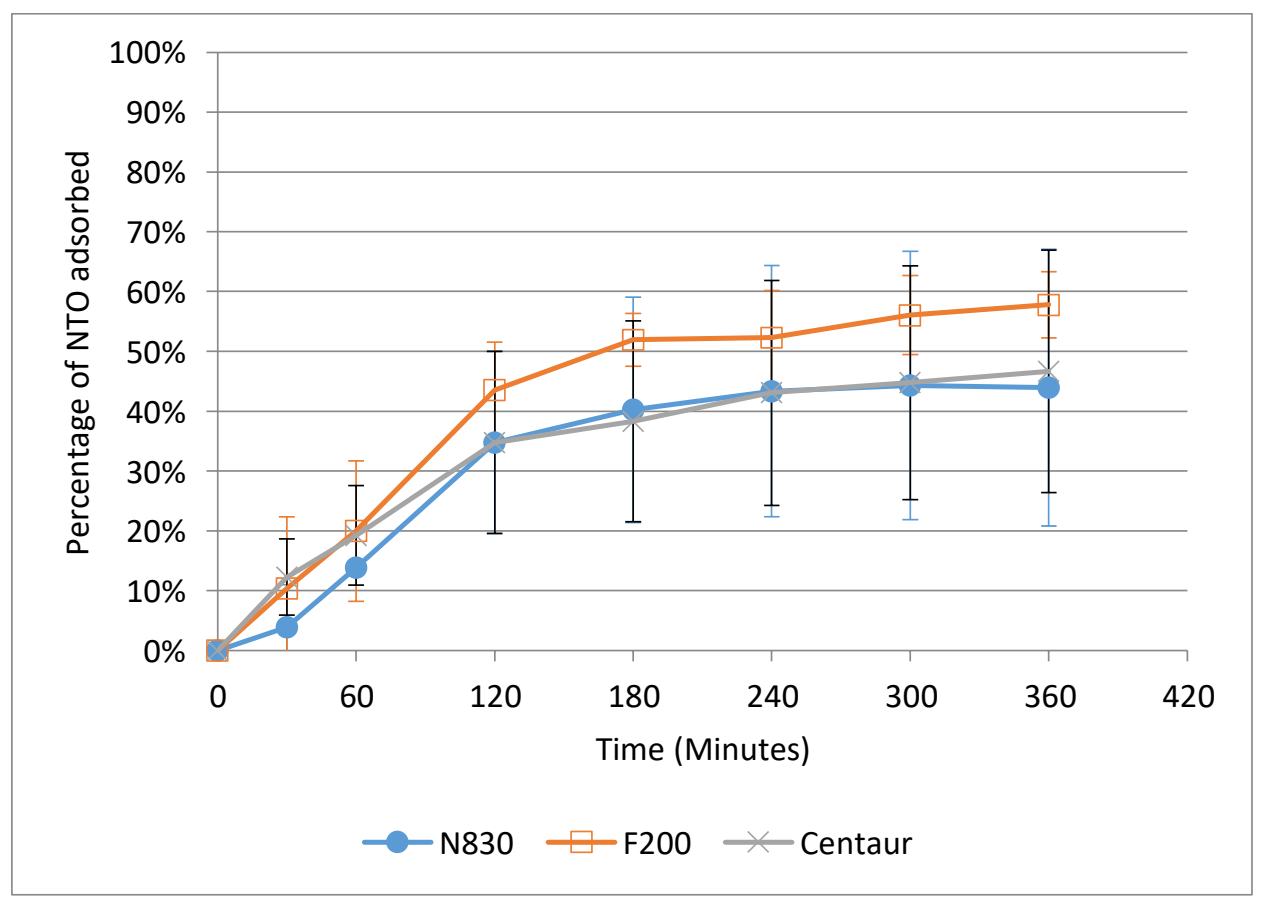


Figure 7: NTO sorption over time from an aqueous solution of $70 \mathrm{mg}$ NTO. $\mathrm{L}^{-1}$ All tests conducted in triplicate.

\subsection{Adsorption Kinetics}

As established by Ho and McKay (Ho and McKay, 1998), the timed adsorption data was plotted using first order, pseudo-first order, second order and pseudo-second order equations. When plotting the data linearly, regression factors introduce simplifications to the model that can obscure the true behaviour of the adsorption reaction. It is therefore necessary to compare the calculated value of the y-axis intercept against the empirical data to confirm the kinetics to which the reaction is best fitted. RDX and DNAN both fit to a first order equation over all of the concentrations tested with a constant proportion of IHE removed from solution over time and this correlates with previously published work on DNAN adsorption (Boddu et al., 2009). These results indicated that film diffusion is the limiting factor for adsorption at the concentrations tested. Comparison of calculated values and those obtained during the tests show the best fit to be a pseudo first order equation for both RDX and DNAN. Therefore, the availability of the AC's surface also influenced the adsorption rate rather than being entirely driven by the availability of IHE constituent in solution. Adsorption of NTO was found to be highly dependent on initial concentration in solution and did not fit any of the kinetic equations used over the full range of concentration tested. However, at lower concentrations the fit tended towards that of the second-order equation. This would indicate that intra-particle diffusion of NTO through the adsorbent material is the limiting factor in the adsorption reaction due to the rapid formation of a surface monolayer at high initial NTO concentrations (Kannan and Sundaram, 2001). A table of kinetic equation results is available in the supplementary material

\subsection{Timed adsorption of Mixed IHE constituents}

Timed adsorption tests were also undertaken using a mixture of IHE to ascertain if there was any preferential adsorption occurring. All IHE were prepared at the same concentration of $10 \mathrm{mg} . \mathrm{L}^{-1} \mathrm{in}$ order to ensure that any difference in adsorption characteristics shown was due to the physiochemical properties of the material and not due to the concentration present. 
Filtrasorb $200 \mathrm{AC}$

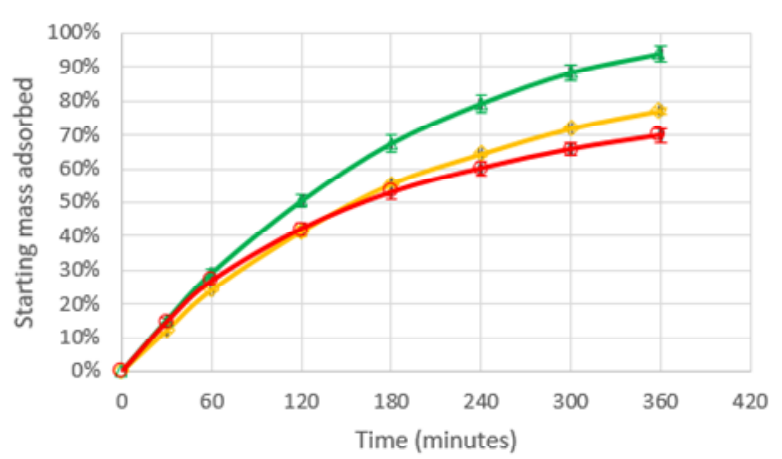

Norit $830 \mathrm{AC}$

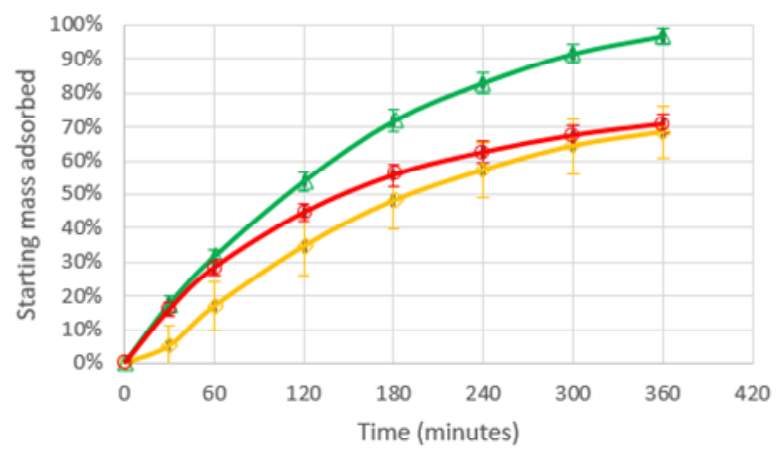

Centaur AC

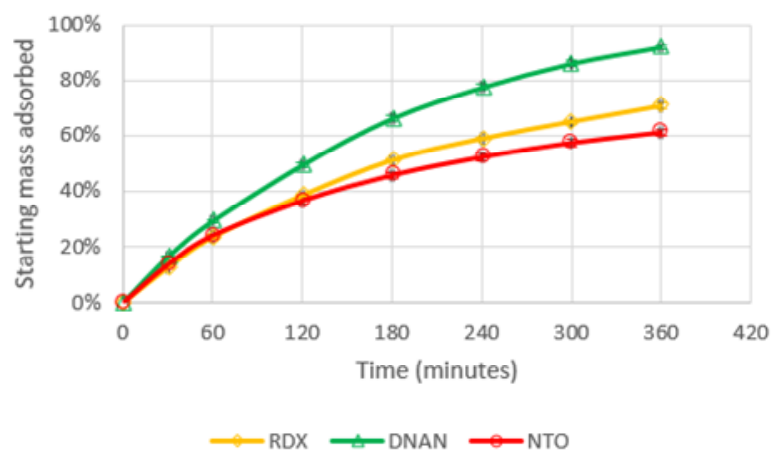

Figure 8: A comparison of the adsorption of the three IHE materials for a) Norit 830 b) Filtrasorb 200 and c) Centaur carbons

The timed adsorption tests show that DNAN is adsorbed faster than the other two IHE constituents tested across all ACs (Figure 8). This is likely due to the increased electron density exhibited by DNAN due to the presence of a six membered ring structure promoting Van der Waals attraction to the AC surface. RDX and NTO appear to be adsorbed at a similar rate across all ACs and in all cases the presence of more than one IHE in the mixture did not alter the properties of adsorption compared to the individual tests carried out. Therefore, the adsorption processes taking place can be considered independent of one another.

\section{Conclusions}

The experiments showed that all the commercial ACs tested are capable of removing IHE constituents from solution in water with the rate of removal dependent upon the initial concentration of IHE in solution. At the concentrations expected in LAP wastewater, RDX can be adsorbed from solution by any of the ACs tested due to the low concentration relative to other IHE constituents with the Freundlich isotherm providing the best fit to design a treatment system. It was found that DNAN adsorption is step limited by film diffusion due to its non-polar nature and is best modelled with the use of the Langmuir isotherm. Adsorption of NTO is step limited by the rate of intra-particle diffusion 
inside the AC grain. This is because the charge differential of NTO when in solution in water means that it passes through the boundary film layer easily. This ease of movement can cause the concentration gradient on either side of the boundary film layer to fluctuate, leading to adsorption/desorption cycles at initial concentrations greater than $140 \mathrm{mg} \cdot \mathrm{L}^{-1}$ as are expected in wastewater from LAP facilities. Despite this, the Freundlich isotherm was found to provide the best fit to NTO adsorption data for use in designing adsorption facilities. It was shown that there was no interaction between the adsorption methods of the three IHE constituents when present in a mixed solution compared to individual tests and that DNAN was adsorbed the fastest from mixed solution due to the preference for film diffusion. This work has shown that there is not a technical or scientific barrier to adsorptive treatment to IHE contaminated wastewater from a LAP plant. Possible barriers to the use of currently available commercial ACs come from the high concentrations of NTO in solution making the mass of AC required uneconomical for large scale or continuous production facilities. Despite this, smaller facilities generating lower volumes of wastewater or at lower frequency, may still be able to use AC as an IHE wastewater treatment method. Therefore, alternative carbon sources that reduce the cost of AC should be investigated, alongside potential preferential adsorption of NTO in a pre-treatment step, in order to make adsorption a commercially viable water treatment process for IHE wastewater.

\section{Acknowledgements}

This work was supported by Cranfield University. The authors would like to thank Dr. Nathalie Mai for her contribution to analysis of samples.

\section{References}

Ahmed, M.B., Zhou, J.L., Ngo, H.H., Guo, W., Chen, M., 2016. Progress in the preparation and application of modified biochar for improved contaminant removal from water and wastewater. Bioresour. Technol. 214, 836-851. https://doi.org/10.1016/j.biortech.2016.05.057

Ahn, S.C., Cha, D.K., Kim, B.J., Oh, S.-Y., 2011. Detoxification of PAX-21 ammunitions wastewater by zero-valent iron for microbial reduction of perchlorate. J. Hazard. Mater. 192, 909-914. https://doi.org/10.1016/j.jhazmat.2011.05.104

Ali, I., Asim, M., Khan, T.A., 2012. Low cost adsorbents for the removal of organic pollutants from wastewater. J. Environ. Manage. 113, 170-183. https://doi.org/10.1016/j.jenvman.2012.08.028

Altmann, J., Ruhl, A.S., Zietzschmann, F., Jekel, M., 2014. Direct comparison of ozonation and adsorption onto powdered activated carbon for micropollutant removal in advanced wastewater treatment. Water Res. 55, 185-193. https://doi.org/10.1016/j.watres.2014.02.025

Arthur, J.D., Mark, N.W., Taylor, S., Šimunek, J., Brusseau, M.L., Dontsova, K.M., 2017. Batch soil adsorption and column transport studies of 2,4-dinitroanisole (DNAN) in soils. J. Contam. Hydrol. 199, 14-23. https://doi.org/10.1016/j.jconhyd.2017.02.004

Arthur, J.D., Mark, N.W., Taylor, S., Šimůnek, J., Brusseau, M.L., Dontsova, K.M., 2018. Dissolution and transport of insensitive munitions formulations IMX-101 and IMX-104 in saturated soil columns. Sci. Total Environ. 624, 758-768.

https://doi.org/10.1016/j.scitotenv.2017.11.307 
Bannon, D.I., Williams, L.R., 2015. Chapter 4 - Wildlife Toxicity Assessment for 1,3,5-

Trinitrohexahydro-1,3,5-Triazine (RDX), in: Wildlife Toxicity Assessments for Chemicals of Military Concern. pp. 53-86. https://doi.org/10.1016/B978-0-12-800020-5.00004-1

Boddu, V.M., Abburi, K., Fredricksen, A.J., Maloney, S.W., Damavarapu, R., 2009. Equilibrium and column adsorption studies of 2,4-dinitroanisole (DNAN) on surface modified granular activated carbons. Environ. Technol. 30, 173-181. https://doi.org/10.1080/09593330802422993

Bricka, M., Fleming, E.C., 1995. Use of Activated carbon for the treatment of ExplosivesContaminated ground water at the Picatinny Arsenal. Vicksburg, MS.

Cabot Corportion, 2011. Norit ${ }^{\circledR}$ GAC 830 EN.

Calgon Carbon, 2019. Filtrasorb ® 200.

Calgon Carbon, 2015. CENTAUR ® 12x40 Catalytic Granular Activated Carbon.

Chelsea K. Katseanesa, 1, Mark A. Chappellb, , 1, , Bryan G. Hopkinsa, Brian D. Durhamb, Cynthia L. Priceb, Beth E. Porterb, L.F.M., 2016. Multivariate functions for predicting the sorption of 2,4,6-trinitrotoluene (TNT) and 1,3,5-trinitro-1,3,5-tricyclohexane (RDX) among taxonomically distinct soils. J. Environ. Manage. 182, 101.

Chew, S.C., Tennant, M., Mai, N., McAteer, D., Pons, J.-F., 2017. Practical Remediation of 3Nitro-1,2,4-triazol-5-one Wastewater. Propellants, Explos. Pyrotech. https://doi.org/10.1002/prep.201700256

Cronin, M.P., Day, A.I., Wallace, L., 2007. Electrochemical remediation produces a new highnitrogen compound from NTO wastewaters. J. Hazard. Mater. 149, 527-531. https://doi.org/10.1016/j.jhazmat.2007.08.007

Dada, A.O., Olalekan, A.P., Olaunya, A.M., DADA, O., 2012. Langmuir, Freundlich, Temkin and Dubinin-Radushkevich Isotherms Studies of Equilibrium Sorption of Zn 2+ Unto Phosphoric Acid Modified Rice Husk. IOSR J. Appl. Chem. 3, 38-45. https://doi.org/10.9790/57360313845

Davies, P.J., Provatas, A., 2006. Characterisation of 2,4-Dinitroanisole: An Ingredient for use in Low Sensitivity Melt Cast Formulations. Defence Science and Technology Organisation, Defence Science and Technology Organisation, Edinburgh, South Australia.

Dodard, S.G., Sarrazin, M., Hawari, J., Paquet, L., Ampleman, G., Thiboutot, S., Sunahara, G.I., 2013. Ecotoxicological assessment of a high energetic and insensitive munitions compound: 2,4-Dinitroanisole (DNAN). J. Hazard. Mater. 262, 143-150. https://doi.org/10.1016/j.jhazmat.2013.08.043

Felt, D., Johnson, J.L., Larson, S., Hubbard, B., Henry, K., Nestler, C., Ballard, J.H., 2013. Technical Report: Evaluation of Treatment Technologies for Wastewater from Insensitive Munitions Production; Phase 1: Technology Down-Selection (ERDC/EL TR-13-20). Vicksburg.

Fleming, E.C., Cerar, R., Christenson, K., 1996. Technical Report: Removal of RDX, TNB, TNT and HMX from Cornhusker Army Ammunition Plant Waters using Adsorption Technologies (EL-96-5). Vicksburg.

Garcia-Mateos, F., Ruiz-Rosas, R., Marqués, M.D., Cotoruelo, L.M., Rodriguez-Miasol, J., Cordero, T., 2015. Removal of paracetamol on biomass-derived activated carbon : Modeling the fixed bed breakthrough curves using batch adsorption experiments $279,18-30$. https://doi.org/10.1016/j.cej.2015.04.144

Gupta, V.K., Saleh, T.A., 2013. Sorption of pollutants by porous carbon, carbon nanotubes and fullerene- An overview. Environ. Sci. Pollut. Res. 20, 2828-2843. https://doi.org/10.1007/s11356-013-1524-1

Hinshaw, G., Fanska, C., Fiscus, D.E., Sorensen, S.A., 1987. Technical Report: Granular Activated Carbon (GAC) system performance capabilities and optimization (AMXTH-TE-CRB7111).

Ho, Y.S., McKay, G., 1998. Sorption of dye from aqueous solution by peat. Chem. Eng. J. 70, 115124. https://doi.org/10.1016/S1385-8947(98)00076-X

Jain, A., Balasubramanian, R., Srinivasan, M.P., 2016. Hydrothermal conversion of biomass waste 
to activated carbon with high porosity: A review. Chem. Eng. J. 283, 789-805. https://doi.org/10.1016/j.cej.2015.08.014

Kannan, N., Sundaram, M.M., 2001. Kinetics and mechanism of removal of methylene blue by adsorption on various carbons - A comparative study. Dye. Pigment. 51, 25-40. https://doi.org/10.1016/S0143-7208(01)00056-0

Kaplan, A.S., Berghout, C.F., Peczenik, A., 1965. Human Intoxication From RDX. Arch. Environ. Heal. An Int. J. 10, 877-883. https://doi.org/10.1080/00039896.1965.10664112

Koutsospyros, A., Pavlov, J., Fawcett, J., Strickland, D., Smolinski, B., Braida, W., 2012. Degradation of high energetic and insensitive munitions compounds by $\mathrm{Fe} / \mathrm{Cu}$ bimetal reduction. J. Hazard. Mater. 219, 75-81. https://doi.org/10.1016/j.jhazmat.2012.03.048

Lamy, P., Leiber, C.-O., Cumming, A.., Zimmer, M., 1996. Energetic Materials - Technology, Manufacturing and Processing, in: Keicher, T. (Ed.), 27th International Annual Conference of ICT. Karlsruhe, Federal Republic of Germany.

Lee, K.-Y., Coburn, M.D., 1988. 3-Nitro-1,2,4-Triazol-5-one, A less sensitive explosive. 4733610. London, J.O., Smith, D.M., 1985. A toxicological study of NTO. Los Alamos.

Lv, Q., Si, W., He, J., Sun, L., Zhang, C., Wang, N., Yang, Z., Li, X., Wang, X., Deng, W., Long, Y., Huang, C., Li, Y., 2018. Selectively nitrogen-doped carbon materials as superior metal-free catalysts for oxygen reduction. Nat. Commun. 1-11. https://doi.org/10.1038/s41467-01805878-y

Maneerung, T., Liew, J., Dai, Y., Kawi, S., Chong, C., Wang, C.H., 2016. Activated carbon derived from carbon residue from biomass gasification and its application for dye adsorption: Kinetics, isotherms and thermodynamic studies. Bioresour. Technol. 200, 350-359. https://doi.org/10.1016/j.biortech.2015.10.047

Mark, N., Arthur, J., Dontsova, K., Brusseau, M., Taylor, S., 2016. Adsorption and attenuation behavior of 3-nitro-1,2,4-triazol-5-one (NTO) in eleven soils. Chemosphere 144, 1249-1255. https://doi.org/10.1016/j.chemosphere.2015.09.101

Metcalf \& Eddy, 2014. Wastewater Engineering: Treatment and Resource Recovery, 5th ed. McGraw-Hill International Edition, New York.

Meyer, S.A., Marchand, A.J., Hight, J.L., Roberts, G.H., Escalon, L.B., Inouye, L.S., MacMillan, D.K., 2005. Up-and-down procedure (UDP) determinations of acute oral toxicity of nitroso degradation products of hexahydro-1,3,5-trinitro-1,3,5-triazine (RDX). J. Appl. Toxicol. 25, 427-434. https://doi.org/10.1002/jat.1090

Mohan, D., Pittman, C.U., 2007. Arsenic removal from water/wastewater using adsorbents-A critical review. J. Hazard. Mater. 142, 1-53. https://doi.org/10.1016/j.jhazmat.2007.01.006

Mohan, D., Sarswat, A., Singh, V.K., Alexandre-Franco, M., Pittman, C.U., 2011. Development of magnetic activated carbon from almond shells for trinitrophenol removal from water. Chem. Eng. J. 172, 1111-1125. https://doi.org/10.1016/j.cej.2011.06.054

Monteil-Rivera, F., Halasz, A., Groom, C., Zhao, J.-S.J.-S., Thiboutot, S., Ampleman, G., Hawari, J., 2009. Fate and Transport of Explosives in the Environment: A Chemist's View, in: Sunahara, G.I., Lotufo, G.R., Kuperman, R.G., Hawari, J. (Eds.), Ecotoxiciology of Explosives. CRC Press, pp. 5-33. https://doi.org/doi:10.1201/9781420004342.ch2

Morley, M.C., Fatemi, M., 2010. Adsorption of RDX and its Nitroso Metabolites onto Activated Carbon. Pract. Period. Hazardous, Toxic, Radioact. Waste Manag. 14, 90-97. https://doi.org/10.1061/(ASCE)1090-025X(2010)14:2(90)

Morley, M.C., Henke, J.L., Speitel, G.E., 2005. Adsorption of RDX and HMX in rapid small-scale column tests: Implications for full-scale adsorbers. J. Environ. Eng. 131, 29-37. https://doi.org/10.1061/(ASCE)0733-9372(2005)131:1(29)

NATO, 2010. STANAG 4439.

NATO, 2006. AOP-39 Edition 2.

Ncibi, M.C., 2008. Applicability of some statistical tools to predict optimum adsorption isotherm after linear and non-linear regression analysis. J. Hazard. Mater. 153, 207-212. https://doi.org/10.1016/j.jhazmat.2007.08.038 
Payne, Z.M., Lamichhane, K.M., Babcock, R.W., Turnbull, S.J., 2013. Pilot-scale in situ bioremediation of HMX and RDX in soil pore water in Hawaii. Environ. Sci. Process. Impacts 15, 2023. https://doi.org/10.1039/c3em00320e

Pennington, J.C., Brannon, J.M., 2002. Environmental fate of explosives. Thermochim. Acta 384, 163-172. https://doi.org/10.1016/S0040-6031(01)00801-2

Platten, W.E., Bailey, D., Suidan, M.T., Maloney, S.W., 2013. Treatment of Energetic Wastewater Containing 2,4-Dinitroanisole and N-Methyl Paranitro Aniline. J. Environ. Eng. 139, 104-109. https://doi.org/10.1061/(ASCE)EE.1943-7870.0000592

Rajagopal, C., Kapoor, J.C., 2001. Development of adsorptive removal process for treatment of explosives contaminated wastewater using activated carbon. J. Hazard. Mater. 87, 73-98. https://doi.org/10.1016/S0304-3894(01)00179-0

Richard, T., Weidhaas, J., 2014. Biodegradation of IMX-101 explosive formulation constituents: 2,4-dinitroanisole (DNAN), 3-nitro-1,2,4-triazol-5-one (NTO), and nitroguanidine. J. Hazard. Mater. 280, 561-569. https://doi.org/10.1016/j.jhazmat.2014.08.042

Robinson, T., McMullan, G., Marchant, R., Nigam, P., 2001. Remediation of dyes in textile effluent: a critical review on current treatment technologies with a proposed alternative. Bioresour. Technol. 77, 247-255. https://doi.org/10.1016/S0960-8524

Roy F Weston Inc., Wucjik, W.J., Lowe, W.L., Marks, P.J., 1990. Use of activated carbon for treatment of explosives-contaminated groundwater at the Milan Army Ammunition Plant. West Chester, PA.

Saad, R., Radovic-Hrapovic, Z., Ahvazi, B., Thiboutot, S., Ampleman, G., Hawari, J., 2012. Sorption of 2,4-dinitroanisole (DNAN) on lignin. J. Environ. Sci. 24, 808-813. https://doi.org/10.1016/S1001-0742(11)60863-2

Salman, J.M., Njoku, V.O., Hameed, B.H., 2011. Adsorption of pesticides from aqueous solution onto banana stalk activated carbon. Chem. Eng. J. 174, 41-48. https://doi.org/10.1016/j.cej.2011.08.026

Shukla, M.K., Poda, A., 2016. Adsorption of Emerging Munitions Contaminants on Cellulose Surface: A Combined Theoretical and Experimental Investigation. Bull. Environ. Contam. Toxicol. 96, 784-790. https://doi.org/10.1007/s00128-016-1791-x

Singh, S., Jelinek, L., Samuels, P., Stasio, A. Di, Zunino, L., 2012. IMX-104 Characterization for DoD Qualification. Insensitive Munitions Energ. Mater. Technol. Symp. 18.

Son, H.K., Sivakumar, S., Rood, M.J., Kim, B.J., 2016. Electrothermal adsorption and desorption of volatile organic compounds on activated carbon fiber cloth. J. Hazard. Mater. 301, 27-34. https://doi.org/10.1016/j.jhazmat.2015.08.040

Spear, R.J., Louey, C.N., Wolfson, M.G., 1989. A preliminary assessment of NTO as an insensitive high explosive. Maribyrnong, Victoria, Australia.

Sun, L., Chen, D., Wan, S., Yu, Z., 2018. Adsorption Studies of Dimetridazole and Metronidazole onto Biochar Derived from Sugarcane Bagasse: Kinetic, Equilibrium, and Mechanisms. J. Polym. Environ. 26, 765-777. https://doi.org/10.1007/s10924-017-0986-5

Taylor, S., Ringelberg, D.B., Dontsova, K., Daghlian, C.P., Walsh, M.E., Walsh, M.R., 2013. Insights into the dissolution and the three-dimensional structure of insensitive munitions formulations. Chemosphere 93, 1782-1788. https://doi.org/10.1016/j.chemosphere.2013.06.011

Temple, T., Ladyman, M., Mai, N., Galante, E., Ricamora, M., Shirazi, R., Coulon, F., 2018. Investigation into the environmental fate of the combined Insensitive High Explosive constituents 2,4-dinitroanisole (DNAN), 1-nitroguanidine (NQ) and nitrotriazolone (NTO) in soil. Sci. Total Environ. 625, 1264-1271. https://doi.org/10.1016/j.scitotenv.2017.12.264

Tennant, M., Chew, S.C., Krämer, T., Mai, N., McAteer, D., Pons, J.F., 2019. Practical Colorimetry of 3-Nitro-1,2,4-Triazol-5-One. Propellants, Explos. Pyrotech. 44, 198-202. https://doi.org/10.1002/prep.201800239

Wallace, L., Cronin, M.P., Day, A.I., Buck, D.P., 2009. Electrochemical Method Applicable to Treatment of Wastewater from Nitrotriazolone Production. Environ. Sci. Technol. 43, 1993- 
1998. https://doi.org/10.1021/es8028878

Winstead, B., 2011. NTO: An Environmental Odyssey, in: NDIA Systems Engineering Conference. San Diego, CA.

Wujcik, W.J., Lowe, W.L., Marks, P.J., Sisk, W.E., 1992. Granular activated carbon pilot treatment studies for explosives removal from contaminated groundwater. Environ. Prog. 11, 178-189. https://doi.org/10.1002/ep.670110311

Yu, H., Ning, X., Li, Y., Ming, J., Wang, Q., Wang, H., Cao, Y., Peng, F., Yang, Y., 2019.

Chemical Science Electronic synergism of pyridinic-and graphitic-nitrogen on N-doped carbons for the oxygen reduction reaction Electronic synergism of pyridinic-and graphiticnitrogen on $\mathrm{N}$-doped carbons for the oxygen reduction reaction 10, 1565-1886. https://doi.org/10.1039/c8sc04596h

Zhou, Y., Zhang, L., Cheng, Z., 2015. Removal of organic pollutants from aqueous solution using agricultural wastes: A review. J. Mol. Liq. 212, 739-762.

https://doi.org/10.1016/j.molliq.2015.10.023 